\title{
CHIASMA FREQUENCY AND VARIABILITY OF MORPHOLOGICAL CHARACTERS IN POPULATIONS OF TWO GRASSHOPPER SPECIES
}

\author{
M. WESTERMAN \\ Department of Genetics and Human Variation, La Trobe University, Bundoora, Vic. \\ 3083, Australia
}

Received 17.v.83

\section{SUMMARY}

Between Individual Variation (BIV) for four morphological characters was scored in a number of populations of the grasshoppers Phaulacridium marginale and Phaulacridium otagoense collected during the 1973 meiotic season from South Island, New Zealand. In all but one case, the variability between individuals is lower in those populations with high chiasma frequencies than in those with low chiasma frequencies. Similar results were obtained for ten populations of $P h$. marginale collected from North Island in 1974. These findings suggest a possible reason why B-chromosomes are only found in ecologically central populations of $P h$. marginale.

\section{INTRODUCTION}

Chiasmata are the physical agent of genetic recombination events in meiotic cells and as such they have been used in a large number of studies to estimate the amount of recombination occurring in natural populations. It has usually been inferred that high chiasma frequencies would reflect high levels of variability in those populations. However, as Rees and Dale (1974) showed in surveys of populations of the grasses Lolium and Festuca, although the release of variability may initially be high in populations with high levels of recombination, natural selection would usually act to fix particular genotypes and thus reduce the overall level of variability in those populations. Conversely, those populations with low chiasma frequencies would appear to preserve variability by having less disruption of supergene complexes. One would thus then observe a negative relationship between chiasma frequency and levels of variability in a population.

Few data comparable to those of Rees and Dale have been reported for animal species though those of Price and Bantock (1974) show a similar negative correlation between chiasma frequency and levels of polymorphisms in populations of Cepaea nemoralis. Since a number of population samples of the endemic New Zealand grasshopper Phaulacridium marginale had been collected for a study of the effect of supernumerary heterochromatin on chiasma frequency, it was decided to measure four morphological characters of these males to determine whether there was any relationship between the Between Individual Variances for these metrics and the population chiasma frequencies. 


\section{MATERIAls AND METHOdS}

Population samples of $\mathrm{Ph}$. marginale and $\mathrm{Ph}$. otagoense were collected from a number of localities from South Island, New Zealand during the 1973 meiotic season (for details, see Westerman, 1974). Testes were scored for mean cell chiasma frequencies as well as for presence of both Bchromosomes and supernumerary heterochromatic segments. The cadavers of the sampled males (usually twenty) were then used to measure four morphological characters: (a) mid-dorsal length of pronotum, (b) left lateral pronotum length, (c) left tegmen length and (d) left hind femur length (see Westerman, 1974). These metrics were used to measure variability among exo-phenotypes within populations. Similar measurements were made on a further ten population samples collected from North Island, New Zealand, during the 1974 meiotic season (for details, see Westerman, 1975).

\section{TABLE 1}

Coefficients of variation for each of four morphological characters scored in population samples of Ph. marginale and Ph. otagoense. (Population codes and chiasma frequency data are from Westerman, 1974, and Westerman, 1975)

\begin{tabular}{|c|c|c|c|c|c|}
\hline Population & $(\mathrm{a})^{*}$ & (b) & (c) & (d) & $\begin{array}{l}\text { Chiasma } \\
\text { frequency }\end{array}$ \\
\hline \multicolumn{6}{|c|}{ (i) $P h$. marginale-1973 } \\
\hline AJ & $7 \cdot 03$ & $7 \cdot 16$ & $10 \cdot 74$ & $5 \cdot 07$ & 15.05 \\
\hline LT & 4.85 & 5.73 & $10 \cdot 14$ & $3 \cdot 64$ & $15 \cdot 71$ \\
\hline LL & $7 \cdot 33$ & $7 \cdot 13$ & $14 \cdot 75$ & $4 \cdot 73$ & $15 \cdot 73$ \\
\hline $\mathrm{AW}$ & 4.87 & 8.48 & $13 \cdot 78$ & 4.51 & $15 \cdot 39$ \\
\hline MA & 7.06 & $7 \cdot 18$ & $12 \cdot 50$ & $3 \cdot 85$ & $15 \cdot 36$ \\
\hline SA & $7 \cdot 84$ & $9 \cdot 53$ & $11 \cdot 26$ & 4.44 & 14.89 \\
\hline PL & $7 \cdot 28$ & 6.62 & $13 \cdot 01$ & $4 \cdot 30$ & $15 \cdot 23$ \\
\hline AO & $4 \cdot 65$ & 6.55 & $8 \cdot 33$ & $3 \cdot 15$ & $15 \cdot 36$ \\
\hline LP & $7 \cdot 87$ & $7 \cdot 04$ & $16 \cdot 54$ & $5 \cdot 35$ & $15 \cdot 25$ \\
\hline \multicolumn{6}{|c|}{ (ii) Ph. otagoense-1973 } \\
\hline NR & $4 \cdot 05$ & 4.65 & 11.90 & $2 \cdot 73$ & $16 \cdot 73$ \\
\hline TP & $4 \cdot 05$ & 5.06 & $9 \cdot 78$ & $2 \cdot 32$ & $16 \cdot 29$ \\
\hline OT & 2.99 & $3 \cdot 11$ & $5 \cdot 56$ & $2 \cdot 44$ & $17 \cdot 23$ \\
\hline LP10 & 4.02 & 4.49 & $6 \cdot 48$ & $2 \cdot 19$ & $17 \cdot 59$ \\
\hline OM & 3.73 & $5 \cdot 07$ & $10 \cdot 49$ & $2 \cdot 68$ & $16 \cdot 98$ \\
\hline BF & $2 \cdot 51$ & 4.45 & 4.45 & 1.87 & $17 \cdot 19$ \\
\hline GG & $4 \cdot 68$ & $6 \cdot 47$ & $11 \cdot 11$ & $3 \cdot 15$ & $16 \cdot 60$ \\
\hline LC & $2 \cdot 59$ & $4 \cdot 73$ & $5 \cdot 51$ & $2 \cdot 57$ & $17 \cdot 80$ \\
\hline \multicolumn{6}{|c|}{ (iii) Ph. marginale-1974 } \\
\hline BJ & $6 \cdot 86$ & $7 \cdot 69$ & 11.47 & $4 \cdot 37$ & 14.97 \\
\hline KA & $5 \cdot 85$ & $6 \cdot 19$ & 12.91 & $4 \cdot 27$ & $15 \cdot 29$ \\
\hline PB & $5 \cdot 68$ & 6.46 & 11.46 & 4.02 & $15 \cdot 31$ \\
\hline KO & $5 \cdot 52$ & 5.06 & $9 \cdot 18$ & 3.57 & $15 \cdot 62$ \\
\hline SM & 4.99 & $4 \cdot 58$ & $11 \cdot 06$ & 3.94 & $15 \cdot 75$ \\
\hline SB & $4 \cdot 50$ & 4.52 & $8 \cdot 66$ & $3 \cdot 35$ & $16 \cdot 05$ \\
\hline GA & 4.43 & 3.92 & $9 \cdot 07$ & $3 \cdot 29$ & 16.09 \\
\hline NU & $5 \cdot 39$ & $5 \cdot 67$ & $10 \cdot 39$ & $3 \cdot 85$ & $15 \cdot 58$ \\
\hline UR & 5.05 & $6 \cdot 28$ & $10 \cdot 36$ & 4.29 & $15 \cdot 39$ \\
\hline AO & 5.43 & $5 \cdot 45$ & $10 \cdot 32$ & $4 \cdot 15$ & $15 \cdot 48$ \\
\hline
\end{tabular}

* See Materials and methods. 


\section{RESULTS AND DISCUSSION}

Since all four metrics chosen were length measures it is possible that the variance of each character will be affected by the overall size of individuals in a particular population. It was decided therefore to correct for this by expressing the data as Coefficients of Variation (see Steel and Torrie, 1960). The results of the 1973 collections of $P h$. marginale and $P h$. otagoense are shown in tables 1 (i) and 1(ii) respectively. It should be noted here that the newly described species $P h$. otagoense (see Westerman and Ritchie, 1983) has been referred to in previous publications as the "small morph" of $P h$. marginale. The results of the 1974 collections of $P h$. marginale from North Island are given in table 1(iii).

These coefficients of variation were then plotted against mean cell chiasma frequency for each population (data from Westerman, 1974 and 1975) and the regression lines calculated and fitted (see figs. 1 and 2). Consideration of these two figures shows that with one exception (Ph. marginale, fig. 1(c) all the regression lines plotted have a negative slope. Only one of the slopes for the 1973 data is significant $(P h$. otagoense, Fig. 1(c) but all four of the 1974 lines have a significant negative slope. Similar, negative correlations were also obtained between coefficients of variation and mean cell chiasma frequency for a limited sample of four populations of $P h$. marginale sampled in the 1972 meiotic season.

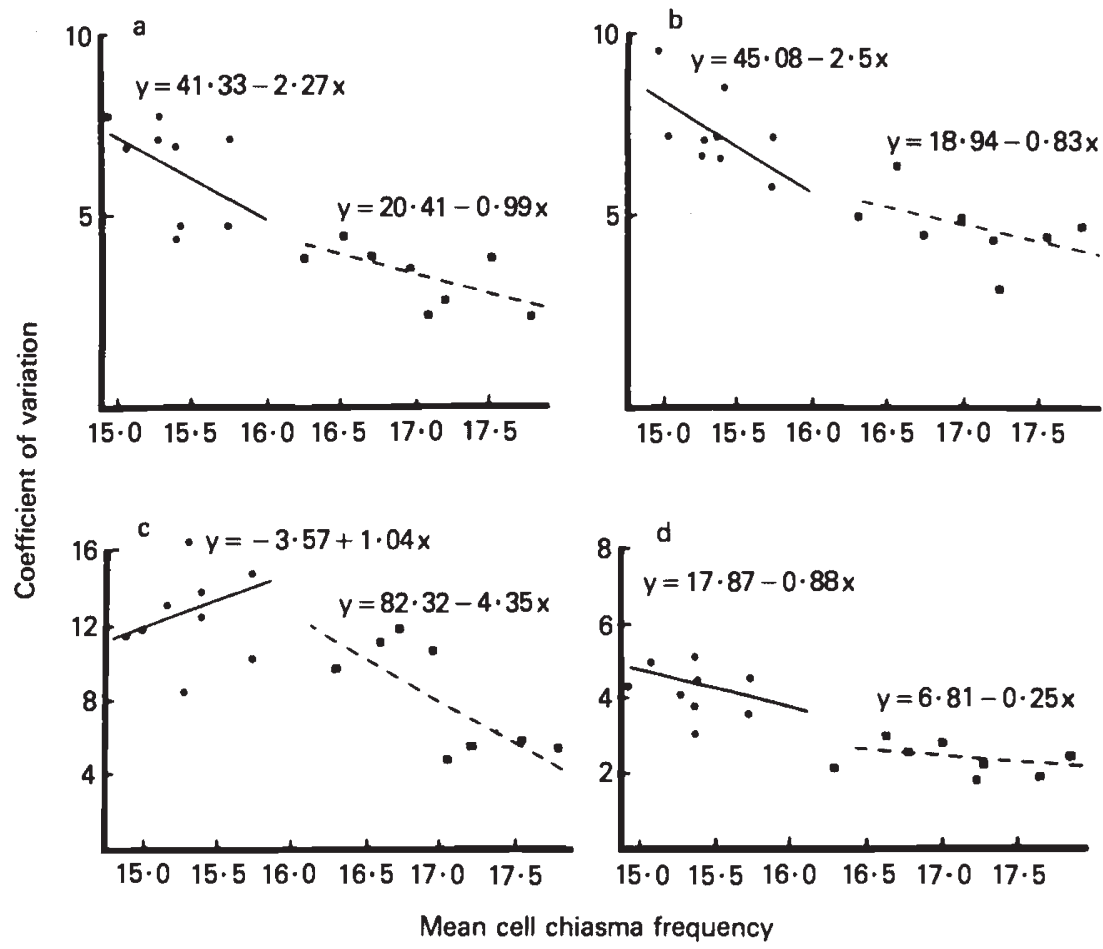

FIG. 1. Between individual variance for four morphological characters regressed on mean cell chiasma frequency in populations of $P h$. marginale $(O)$ and $P h$. otagoense $(\square)$ collected in 1973. 


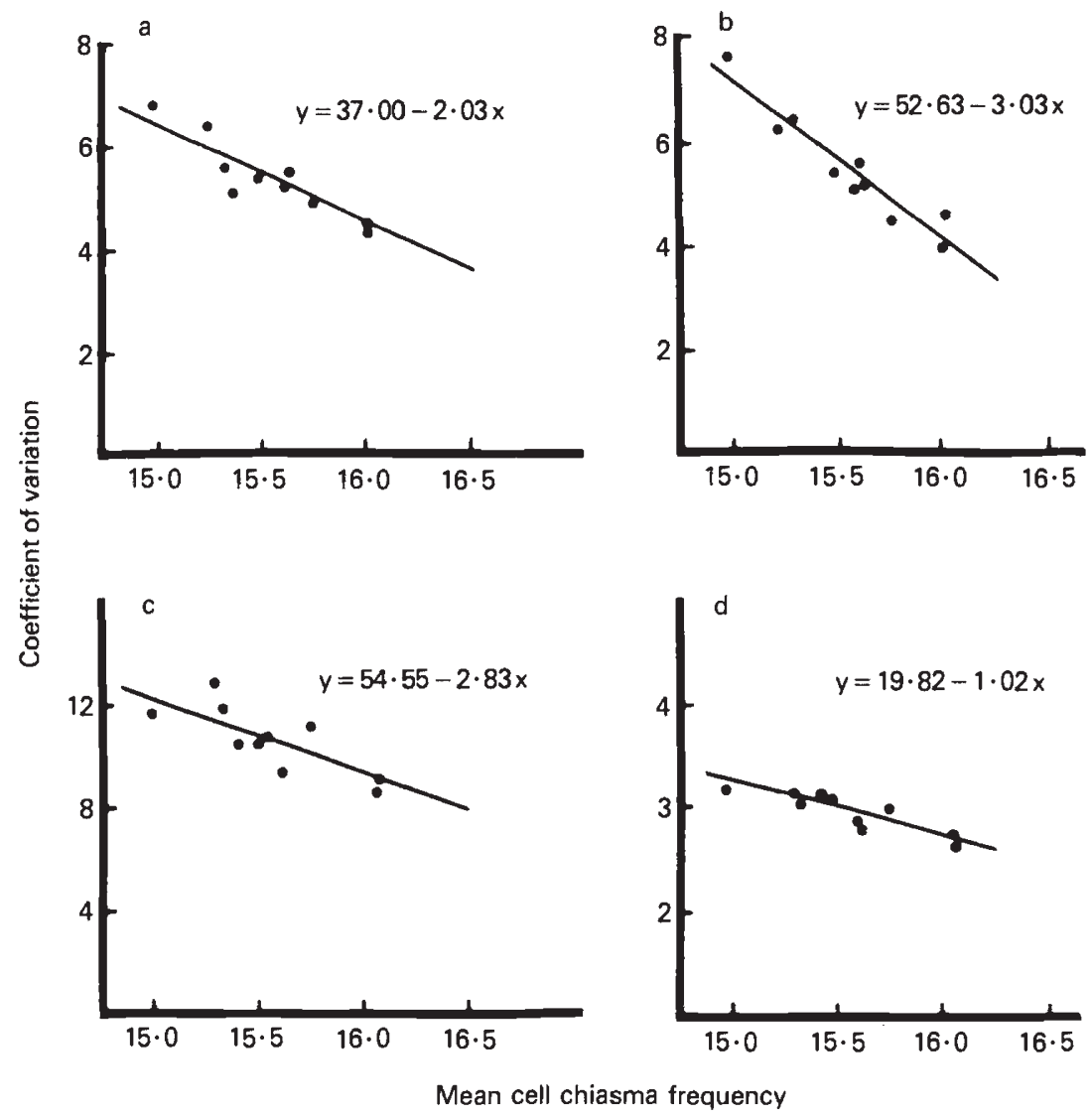

FIG. 2. The 1974 data for Ph. marginale.

These results are in agreement with those of Rees and Dale (1974) for the grasses Lolium perenne and Festuca pratensis where the variability between individuals within populations was lower in those populations with high chiasma frequencies and higher in those populations with low chiasma frequencies. Similar trends of decreasing variability of populations with increasing chiasma frequency can also be seen in Cepaea nemoralis population data reported by Price and Bantock (loc. cit.), and in the mottled grasshopper $M$. maculatus by Hewitt and John (1970). In the former case there is a negative correlation between population chiasma frequency and index of polymorphism (data from their tables 1 and 2). In the latter case, although B-chromosomes were shown to have "no obvious immediate effect on the exo-phenotype", a consideration of table I, Hewitt and John (1970) reveals that in a large number of cases (16 out of 24) the Between Individual Variance of "non-B" individuals is greater than that of " $\mathrm{B}$ " individuals. Although no chiasma frequency data are given for these five Sutton populations, it is stated that "individuals with supernumeraries have higher mean cell chiasma frequencies than their non-B compatriots from the same population". As noted by Rees and Dale, all of these negative correlations are to be expected if higher chiasma frequencies led to greater 
release of variability in populations, some of which was then "fixed" by natural selection. Populations with lower chiasma frequencies would thus tend to have their variability comparatively preserved as less recombination events occur in the genome.

The amount of variability released in populations with higher levels of recombination would be enhanced if the "extra" chiasmata occurred in portions of the genome not normally recombined. Although no studies on chiasma localisation in the genus Phaulacridium have been done which are comparable with the detailed analyses in the genus Caledia (see Shaw and Knowles, 1976; Coates and Shaw, 1982) it is known that in Phaulacridium too chiasmata tend to be localised. In the smaller chromosomes the localisation is distal with respect to the centromere, the larger telocentrics tending to have both proximally and distally localised chiasmata. Most of these terminal chiasmata may have little or no role to play in the normal recombination process other than to ensure orderly segregation of homologues. The patterns of chiasma localisation observed mean that the interstitial regions of the majority of chromosomes normally show little genetic recombination. Increases in mean cell chiasma frequency generally result in chiasmata being formed in these interstitial regions with concommitant breakup of supergene complexes normally inherited as units. Again this situation is similar to that described in Lolium and Festuca by Rees and Dale (1974), in wheat by Zarchi et al., $(1972,1974)$ and in rye by Jones (1974).

The presence of B-chromosomes or supernumerary segments in individuals of the genus Phaulacridium also leads to higher mean cell chiasma frequencies and to the presence of more cross-over events in the interstitial regions of the larger and intermediate sized bivalents. Such increases in recombination might facilitate rapid adaptation and greater fitness in the short term but would also be responsible for a loss of longer term adaptability in the population as higher levels of homozygosity are achieved by fixation. In this latter case, the high chiasma frequencies seen in populations may well be a relict of an earlier condition (Rees and Dale, loc. cit.). In $\mathrm{Ph}$. marginale and $\mathrm{Ph}$. otagoense, B-chromosomes or extra segments which raise chiasma frequency are only found in populations in the ecological "centre" of the species range (Westerman, 1975). From this it could be argued that break-up of coadapted gene complexes in the interstitial regions of chromosomes allows for closer adaptation of populations to varied habitats in the centre of the species range. In contrast, however, the presence of polymorphisms for B's and segments in populations on the ecological periphery would be less likely to be tolerated where a premium would be placed on the maintenance of heterozygous gene combinations.

Release of variability by high chiasma frequencies may thus make possible the fixation, by selection, of more adaptive but, at the same time more homogeneous and homozygous genotypes. These findings also suggest a possible reason why B-chromosomes are only found in ecologically central populations of $\mathrm{Ph}$. marginale.

Acknowledgements. The collection of material were facilitated by an Australian Research Grant Committee award D72/15255. I would like to thank Professor H. Rees for his comments on the manuscript. 


\section{REFERENCES}

COATES, D. J. AND SHAW, D. D. 1982. The chromosomal component of reproductive isolation in the grasshopper Caledia captiva I. Meiotic analysis of chiasma distribution patterns in two chromosomal taxa and their $\mathrm{F}_{1}$ hybrids. Chromosoma (Berl.), 86, 509-531.

HEWITT, G. M. AND JOHN, B. 1970. The B-chromosome system of Myrmeleotettix maculatus (Thunb.). IV. The dynamics. Evolution, 24, 169-180.

JONES, G. H. 1974. Correlated components of chiasma variation and the control of chiasma distribution in Rye. Heredity, 32, 375-387.

PRICE, D. J. AND BANTOCK, C. R. 1975. Marginal populations of Cepaea nemoralis (L) on the Brendon Hills, England. II. Variation in chiasma frequency. Evolution, 29, 278-286.

REES, H. AND DALE, P. J. 1974. Chiasmata and variability in Lolium and Festuca populations. Chromosoma (Berl.), 47, 335-351.

SHAW, D. D. AND KNOWLES, G. R. 1976. Comparative chiasma analysis using a computerised optical digitiser. Chromosoma (Berl.), 59, 103-127.

STEEL, R. G. D. AND TORRIE, J. H. 1960. Principles and Procedures of Statistics. McGraw-Hill, London.

WESTERMAN, M. 1974. Population cytology of the genus Phaulacridium. II. Phaulacridium marginale (Walker); chiasma frequency studies from South Island, New Zealand. Chromosoma (Berl.), 46, 207-216.

Westerman, M. 1975. Population cytology of the genus Phaulacridium. Phaulacridium marginale (Walker). The North Island populations. Heredity, 53, 165-172.

WESTERMAN, M. AND RITCHIE, J. M. 1983. The taxonomy, distribution and origins of two species of Phaulacridium (Orthoptera: Acrididae) in the South Island of New Zealand. Biol. J. Linn. Soc. (in press).

ZARCHI, Y., SIMCHEN, G., HILLEL, J. AND SCHAAP, T. 1972. Chiasmata and the breeding system in wild populations of diploid wheats. Chromosoma (Berl.), 38, 77-94.

ZARCHI, Y., HILLEL, J. AND SIMCHEN, G. 1974. Supernumerary chromosomes and chiasma distribution in Triticum speltoides. Heredity, 33, 173-180. 